\title{
Novas direções na Sociologia da Arte'
}

\author{
New directions in the sociology of art
}

\author{
Howard Becker
}

\section{Tradução de Franklin Lopes ${ }^{a}$}

É costumeiro demandar por "novos caminhos" no estudo disto ou daquilo, como se as velhas direções nos tivessem falhado, como se nós estivéssemos condenados a não chegar a lugar nenhum. Neste caso, eu não aceito tal premissa. Temos um número de antigas direções que parecem muito úteis para mim, ainda capazes de orientar as pessoas rumo a excelentes peças de pesquisa. No entanto, os organizadores desse colóquio queriam “Novas Direções” e eu farei o meu melhor para atendê-los.

Então, eu vou propor uma "nova direção", que é uma abordagem genética para o estudo sociológico das obras e mundos da arte. Tal abordagem engloba dois tipos de pesquisas. A primeira é o estudo ascendente ${ }^{2}$, de como alguns fenômenos artísticos - uma obra, um estilo, um gênero, um completo mundo da arte - vêm a ser, passo a passo; todas as coisas que são feitas, na ordem em que são feitas pelas pessoas que as fazem, no curso do objeto de estudo (que eu vou tratar a partir de agora como uma "obra", compreendida como abrangendo a variedade de coisas que acabei de mencionar), vir a ser o que é. Sugeri, em Art Worlds ${ }^{3}$, que é interessante pensar sobre essa parte de uma história da obra, do ponto de vista do artista, como a edição (no sentido que os fotógrafos dão a essa palavra e ideia), olhando para todas as decisões, conscientes ou não, que o artista faz e que fazem a obra (ou gênero etc., não vou repetir isso de agora em diante) vindo a ser o que ela é. No caso de obras coletivas, onde ninguém tem muita certeza, ou quando isso não estiver acordado, sobre quem é o artista - você deveria naturalmente estudar as decisões das várias pessoas ou grupos envolvidos e como as disputas entre eles são resolvidas. No caso de um gênero ou estilo, você deveria incluir todas as pessoas cujo trabalho e ideias contribuíram para o seu desenvolvimento, incluindo entre

1 Apresentado no Colóquio da ESA (École Spéciale d’Architecture, Paris) em Paris, abril de 2003

a Professor de Sociologia no Instituto Federal de Educação, Ciência e Tecnologia do Maranhão e doutorando em Ciências Sociais na Universidade Federal do Maranhão.

2 No original, upstream.

3 Edição portuguesa: Becker, Howard. Mundos da arte. Livros Horizonte: Portugal, 2010, 328 p. 
eles, naturalmente, os esteticistas e historiadores que conceberam uma coleção de tendências tal como um nome e pedigree.

Por outro lado, movendo-se em sentido descendente 4 a partir da obra, você deveria estudar a sua história contínua, o que aconteceu a ela depois de qualquer data que você decidir que é pertinente para considerá-la "feita”, para que uma versão estendida da técnica de traçar uma proveniência seja uma metáfora apta. Isto é, depois que "isso" é feito, o que acontece com isso?

Algumas observações preliminares. Antes de tudo, não proponho que esta seja uma ideia única e original. Longe disso. Eu fiz uso das ideias e pesquisas de muitos outros que chegaram a essa posição, como ficará claro, e eu mesmo já disse muitas dessas coisas.

Mas, embora não haja nada novo sob o sol, muitas vezes é útil colocar as ideias em uma estrutura provisória que indique suas relações e semelhanças. Podemos, então, lucrar, a partir de novas comparações confrontantes de justaposições sistemáticas, utilizando-as para perceber processos e fenômenos que normalmente estamos muito acostumados a observar e aprender com eles sobre as novas dimensões das coisas nas quais estamos interessados.

Um segundo ponto. Não é óbvio onde cessa o ascendente e o descendente começa. A história de qualquer trabalho ou estilo ou gênero começa onde? Onde quer que nós escolhamos para começar, sempre podemos encontrar algo que veio antes que seja relevante para a história que vamos contar, e há algo que veio ainda mais tarde que poderia igualmente bem ser considerado como um ponto de partida apropriado. Podemos, é claro, considerar o presente momento como o lugar onde o movimento descendente termina para fins analíticos. Isto não tem uma intenção desanimadora, mas é simplesmente para que se reconheça que as escolhas são arbitrárias, ditadas por nossas perguntas, os dados e o tempo disponível, mas não por alguma coisa inerente aos acontecimentos que estamos estudando (isto é como a questão da periodização na história).

O que se pode esperar como resultado razoável desse exercício? Eu não acho que ele vá produzir novos resultados surpreendentes ou uma nova Grande Teoria da Arte e Sociedade. O que eu espero, em vez disso, é sugerir algumas trajetórias típicas, estágios típicos que talvez possamos encontrar em nossa investigação de uma nova área empírica - e não uma "lei" sobre como gêneros necessariamente se desenvolvem a partir de uma autêntica expressão de algo para uma versão

4 No original, downstream. 
comercializada disso, por exemplo, mas a descrição de como esse tipo de processo funciona quando e onde ele ocorre.

\section{ASCENDENTE}

Começando pelo material a ser analisado, podemos ver atrás os passos que o produziram. Uma boa maneira de fazer isso é pensando em tudo o que acontece com a obra, e é então incorporado a ela, como outra opção (ou outras) feita(s), embora muitas vezes a escolha não seja consciente e deliberada, mas em vez disso a utilização de um material ou técnica ou ideia que é tão convencional como estar quase "inconsciente" (se posso usar essa palavra sem algum sobretom psicológico pesado rastejando dentro).

É axiomático, no estudo sociológico dos processos de produção, que os mais frutíferos momentos para o sociólogo sejam aqueles em que os participantes discordam, discutem, lutam. Porque nesses momentos algum acordo, se existiu de fato ou foi apenas esperado, foi quebrado. Quando as pessoas dizem um ao outro, "eu esperava que você fizesse X [ser capaz de tocar as notas que a minha partitura pede ou, alternativamente, escrever notas que eu possa tocar]", uma expectativa subjacente em que a interação se baseava e que não era colocada em discussão, e que deve muito provavelmente ter sido "inconsciente", é revelada para a nossa análise.

Onde tais momentos de conflito ocorrem normalmente? Eles muitas vezes surgem a nível social na margem entre dois grupos - por exemplo, na interação de profissionais de vários tipos na produção de obras de arte: entre fornecedores de materiais e artistas, entre artistas e leigos, entre artistas e pessoas que lidam com as finanças do empreendimento artístico. O que é característico aqui é que cada um desses grupos traz à tona um conjunto estabelecido de ideias sobre como as coisas devem ser feitas, quem dá as ordens, como o dinheiro é dividido e distribuído e, assim, acerca de todas as coisas que os participantes de uma empreitada artística conjunta esperam uns dos outros.

Para cada margem, onde o conflito é possível e até provável, podemos supor que existem padrões característicos de luta e resolução e que esse deverá muitas vezes ser um processo histórico pelo qual a luta se transforma em um conjunto de costumes e procedimentos que irão durar por um tempo. Assim, podemos olhar para o processo que vai, eventualmente, produzir uma solução habitual para as lutas atuais sobre a divisão dos rendimentos de uma obra de arte que foram engendradas pela ascensão dos computadores e suas práticas associadas: marketing via internet, a capacidade generalizada para facilitar a cópia de trabalhos, ou a emissão de "amostragens" de trabalhos musicais para criar novos. Assim como 
disputas anteriores, produziram um conjunto de acordos sobre direitos autorais, royalties, direitos de autor, etc.

Essa área é em si tremendamente complicada e eu vou me referir aqui apenas à maravilhosa obra de Richard Caves, o economista, que trouxe todo o arsenal da teoria econômica para fazer frutificar uma variedade de problemas que surgem aqui, bem como as análises de Pierre-Michel Menger sobre o mercado de trabalho para os artistas.

\section{DESCENDENTE}

Podemos começar com a observação bem conhecida de Latour: "o destino do que dizemos e fazemos está nas mãos dos próximos usuários" (Science in Action, p. 29). Ele está falando sobre fatos científicos, mas a observação é igualmente aplicável às obras de arte. Uma vez que passamos o ponto que temos escolhido como o pivô entre a ascendente e a descendente - um comum e bom lugar para colocar esse ponto é quando o trabalho sai das mãos do que convencionalmente é identificado como o criador - podemos escolher um ponto mais tarde como a outra extremidade da trajetória que se deseja estudar. E então nós podemos realizar uma versão estendida do que os historiadores de arte fazem quando constroem uma proveniência para uma pintura. Eles tentam explicar o paradeiro da imagem em todos os momentos, para mostrar uma cadeia ininterrupta de propriedades e possessões físicas: quem comprou de quem, em quais circunstâncias.

Tomei consciência disso como uma possível técnica para os cientistas sociais quando, através do uso inventivo de Hans Haacke, mostrei como uma pintura de Manet tinha se movido através de uma variedade de proprietários, incluindo algumas bem estabelecidas e educadas famílias judias, eventualmente, para ser comprada pelo Museu Amigos da Arte de Colônia (Alemanha), cujo diretor tinha sido um nazista de alta patente. Haacke não fez isso para estabelecer a autenticidade da pintura, que é o objetivo comum de partida de um historiador de arte. Ele usou a técnica como parte de seu projeto maior de mostrar o chão moralmente instável em que o bem-estar financeiro das principais instituições do mundo da arte tinha se estabelecido.

Podemos generalizar um pouco o procedimento de Haacke, sugerindo-o como um método para estudar as bases financeiras das instituições do mundo da arte: verificando a história dos proprietários dos objetos, procurando os principais momentos em que o objeto mudou de mãos, em que poderíamos esperar mudanças nas avaliações e julgamentos estéticos, vão se apresentar muito claramente. 
Outra sequência típica ocorre no desenvolvimento de determinados gêneros, com uma mudança de público e um julgamento moral associado ao trabalho. Aqui refiro-me ao tipo de pesquisa feita por Richard Peterson e David Grazian sobre o problema da autenticidade, em um sentido diferente da arte-histórica, de alguns tipos de músicas "folclóricas", Country e Western, no caso de Peterson, e blues em Grazian. Aqui a música é pensada para ser o reflexo autêntico ou produto de um modo de vida que é etnicamente distinto ou de alguma forma intimamente relacionada com as condições de vida das pessoas que tocam isso, cantam isso, dançam isso, ouvem isso. Parte do prazer que a música produz é o conhecimento do público de que isso é "a coisa real" imune a pressões comerciais, uma verdadeira janela para outra forma de vida. Mas, as pessoas que não vivem essa vida por quererem ver essa “coisa real”, tornam possível e dejável que se venda isso a elas.

E então se inicia um processo no qual músicos, cantores e compositores começam a criar versões da música originalmente autêntica para um público que só a conhece através de gravações. No caso paradoxal estudado por Grazian, pessoas vêm de todo o mundo ouvir "autênticos" blues de Chicago. Eles sabem o que é porque eles têm as gravações que compraram. E eles vêm para Chicago em busca do que está em suas gravações, interpretadas por músicos de blues reais nos verdadeiros clubes de blues, em que todos os outros clientes são as "pessoas reais" de cujas vidas esta música era a expressão autêntica. Como você pode imaginar isso leva os clubes a serem preenchidos por esses "caçadores" do mundo todo, que expulsam as pessoas que estiveram anteriormente lá e chateiam os músicos, insistindo que eles toquem exatamente o que está nas gravações que os levaram até lá. E o clube é, portanto, não mais autêntico e não mais de interesse para as pessoas que assim o destruíram. Um processo semelhante ocorreu em relação à "arte africana autêntica”, a "autêntica arte pré-colombiana” e no que diz respeito a muitos outros tipos de arte.

Um terceiro momento do tipo descendente ocorre quando um objeto é eliminado. "Durabilidade" é muitas vezes um critério da grande arte, mas, mais prosaicamente, durabilidade no sentido físico, é uma contingência que afeta todas as obras. Se algo dura fisicamente, e, portanto, também esteticamente, depende de um grande número de escolhas feitas por uma grande variedade de pessoas. Primeiro de tudo, a obra de arte é muitas vezes destruída. Talvez como um resultado de decisões políticas: são abundantes os exemplos, como a destruição de igrejas e sua associação com as obras de arte na Inglaterra ou Espanha em vários momentos, ou no Afeganistão há pouco tempo. Ray Bradbury vivificou tal problema 
em Fahrenheit ${ }^{\circ} 451$ com a queima de livros e sua salvação através de pessoas que os memorizaram.

Além disso, há o processo inevitável de armazenamento. Todos nós já enfrentamos um momento em que se tornou necessário se livrar de algumas coisas, fazer escolhas de quais livros ou gravações carregar quando nos mudamos, por exemplo. É um problema com o qual se confrontam museus e bibliotecas. Ou eles continuam a crescer para sempre e acomodar um número infinito de coisas novas ou eles se “desfazem” de algumas coisas para ceder espaço ao novo. Este é um lugar onde há certamente momentos em que as formas estabelecidas para fazer isso se tornam desconfortáveis e causam problemas, como quando museus são descobertos se livrando de coisas que lhes foram confiadas para sempre, mas que já não são consideradas boas como antes se pensava. Pior ainda quando, como tantas vezes acontece, cinquenta ou cem anos depois, os gostos e julgamentos tendo trocado de novo, o que se tinha lançado fora se torna objeto de desejo renovado.

Um papel-chave pode ser central aqui, como Gladys e Kurt Lang mostraram, por indivíduos-chave que se tornaram empresários dedicados a manter o trabalho, a memória e a reputação de um artista vivo. No caso deles, eram as esposas de uma geração de gravadores ingleses que fizeram a obra, preservando o trabalho, persuadindo repositórios para aceitá-los e divulgá-los sempre que possível. Da mesma forma, "revivals" da reputação de uma obra ou artista ou gênero são geralmente o resultado de alguém decidindo reavivar o item em questão. Não é uma questão de qualidade, finalmente exibida em sua completude, mas sim de um empreendedor ou mediador ou editor ou diretor ou crítico ou curador decidindo reviver algo, que por qualquer motivo pareça pertinente.

Em termos mais gerais, o movimento de reputações continua incansavelmente, ficam em baixa, voltam a estar em alta e logo caem novamente, como Natalie Heinich demonstrou no caso de van Gogh e Barbara Herrnstein Smith descreveu para os sonetos de Shakespeare (também podemos mencionar as redescobertas de Francis Haskell em Arte).

\section{FINALMENTE...}

O que tenho sugerido aqui não é realmente uma nova direção. Mas o que pode ser novo sobre isso é que eu quero empregar implacavelmente, e sem exceção, uma análise em perspectiva processual e que leve em conta todos os atores no drama da arte.

Por "processual" quero dizer, primeiro, que tudo no mundo social, e a arte não é excessão, muda constantemente. As coisas materiais mudam fisicamente: 
elas se deterioram, são destruídas, são refeitas. Os trabalhos executados estão sujeitos a múltiplas interpretações, ocorrem em locais diferentes, são reescritos por seus autores ou por outros. Assim, não podemos falar de uma obra de arte como uma coisa estável. Existe uma partitura escrita, que talvez possamos chamar de “Tombeau de Couperin”, de Ravel - embora tenhamos que especificar se queremos dizer as seis peças para piano ou as quatro marcadas para a orquestra - mas não será a mesma peça tocada por diferentes pianistas, e não vai soar a mesma em diferentes salas de concerto nem em gravações tocadas em equipamentos diferentes. No entanto, podemos e falamos sobre esse trabalho como se fosse uma coisa estável, mas só porque concordamos, mais ou menos implicitamente, em ignorar essas diferenças. Caso contrário, teríamos de especificar qual a performance da obra, por qual pianista, em que piano gravou, como... .

Outra maneira de dizer isso é reconhecer, como sugerido anteriormente, que a escolha do ponto a partir do qual consideramos a "ascendente" e a "descendente" é arbitrário.

"Processual" também se refere a nós mesmos, como sugeri anteriormente, à idéia de escolha, tal como expressa no termo "edição", que peguei emprestado da prática fotográfica - as escolhas feitas, no caso de uma obra musical, por exemplo, de versões, andamento, interpretação de marcas expressivas e assim por diante. Mas isso é apenas o início de uma lista muito longa, cujo conteúdo tem, em todos os casos, que ser investigado empiricamente.

Pensar em edição nos leva ao segundo ponto, o grande número e variedade de pessoas envolvidas na história de uma obra. Este é um ponto que discuti longamente em Art Worlds. Vou apenas lembrar aqui a lista de créditos no final de um filme. Essa lista é convencional no filme, mas listas semelhantes não são convencionais em outras artes, embora elas poderiam naturalmente ser feitas. A escolha de quem, entre todas as pessoas a serem incluídas em tal lista, é algo arbitrária. Um pouco porque alguns dos atores são claramente mais influentes do que outros. Mas, por outro lado, é importante reconhecer que este é um tipo multiplicativo de funções. Todo mundo é importante e pode ser reconhecido como tal quando algum dos envolvidos na feitura da obra não faz o seu trabalho como esperado. Então todo mundo terá que se ajustar a essa ausência e o trabalho será diferente do que teria sido se todos tivessem feito o esperado.

Estas são coisas que eu acho que a maioria dos sociólogos de arte diria "com certeza!”. Mas há uma diferença entre “com certeza” e seguir estritamente as diretrizes que emanam dessa posição. Segui-las de forma precisa pode ser, finalmente, uma Nova Direção. 